\title{
Comparison of Bioelectrical Impedance and Navy Seal Formula to Measure Body Composition in Medical Students
}

\author{
Abida Shaheen ${ }^{1}$, Nismat Javed ${ }^{2,}{ }^{3}$, Fahad Azam ${ }^{1}$, Afrose Liaquat ${ }^{4}$, Moosa Khan ${ }^{5}$, Syed \\ Mahboob Alam ${ }^{6}$, Sana Mumtaz ${ }^{4}$ \\ 1. Pharmacology and Therapeutics, Shifa College of Medicine, Shifa Tameer-E-Millat University, Islamabad, \\ PAK 2. Internal Medicine, Shifa College of Medicine - Shifa Tameer-E-Millat University, Islamabad, PAK 3. \\ Cardiology, Rawalpindi Institute of Cardiology, Rawalpindi, PAK 4. Biochemistry, Shifa College of Medicine, \\ Shifa Tameer-E-Millat University, Islamabad, PAK 5. Pharmacology and Therapeutics, Jinnah Postgraduate \\ Medical Center, Karachi, PAK 6. Pharmacology and Therapeutics, Shaheed Zulfiqa, Islamabad, PAK
}

Corresponding author: Nismat Javed, nismatjaved@gmail.com

\section{Abstract \\ Objectives}

There are many different ways to measure body composition and bioelectric impedance is one of the most popular methods to measure body ratios. The navy-seal formula is another simple way of measuring body fat ratio which takes into account simple variables such as gender, weight, height, waist, hip and neck circumference. The objective of our study was to compare the results of body fat composition by these two methods.

\section{Materials and methods}

Height and weight were measured in 85 study participants using a wall-mounted stadiometer and digital scale. Body composition measurements were recorded using a simple measuring tape. Participants were then asked to stand on the electrical impedance machine to determine the body fat and muscle mass. Data were analyzed on IBM's statistical package for the social sciences (SPSS) version 23 (IBM, Armonk, NY).

\section{Results}

The Navy-seal formula had slightly higher values for both muscle mass and body fat ratio in both genders and across all body mass index (BMI) categories. Body fat ratio and muscle mass of both genders were similar in underweight, normal, over weight and obese participants. In males, the results on two instruments showed more similarity with the increase in BMI, whereas, in females, the results of the two methods were more similar in the normal weight category.

Received 05/01/2019 Review began 05/03/2019 Review ended 05/09/2019 Published 05/22/2019

(c) Copyright 2019

Shaheen et al. This is an open access article distributed under the terms of the Creative Commons Attribution License CC-BY 3.0., which permits unrestricted use, distribution, and reproduction in any medium, provided the original author and source are credited.

\section{Conclusion}

Navy-seal formula and bioelectrical impedance are both simple and reliable instruments to measure body composition in adults. The navy-seal formula can be used to screen individuals with high-fat body fat ratio whereas bioelectric impedance can be used to measure the body composition for personal monitoring.

Categories: Endocrinology/Diabetes/Metabolism, Miscellaneous, Epidemiology/Public Health Keywords: bioelectrical impedance, navy seal formula, body fat ratio, muscle mass, body mass index

\section{Introduction}


There has recently been a gradual rise in the global prevalence of obesity and many associated health problems such as hypertension insulin resistance, and type 2 diabetes mellitus and dyslipidemia [1-5]. Body weight alone is not a very good indicator of health as its measurement cannot distinguish between the weight of body fat and weight of lean body mass or muscle. Even if the overall weight is within normal ranges, high body ratio can still increase the risk of insulin resistance, central obesity, elevated triglyceride levels, elevated blood pressure, proinflammatory and prothrombin state [6-7].

Body fat can be measured by different means such as skin calipers, bioelectric impedance, hydrostatic weighing, Air-Displacement Plethysmography and Dual Energy X-Ray Absorptiometry (DEXA). Most of these methods are quite costly and time consuming so there is a need to develop a simpler way to assess body fat ratios.

One of the simplest methods to measure body fat percentage is using bioelectrical impedance analysis (BIA), which underpins the principle of opposing electric current through different body tissues [8]. Body composition, the measurement of body fat in relation to lean body mass is calculated from the difference in conductivity as fat-free body mass offers minimal impedance to electrical signals owing to a large amount of water and electrolytes whereas adipose tissue shows very low conductivity to electrical current [9].

Another simpler way of measuring body fat ratio is by using the Navy-seal formula which only requires simple variables such as age, gender, height, body weight and circumferences of waist, hip and neck. Calculation of body for males is by using the formula of $86.010 \mathrm{x} \log 10$ (abdomen - neck) $70.041 \mathrm{x} \log 10$ (height) +36.76 while for females it is $163.205 \mathrm{x} \log 10$ (waist + hip - neck) $-97.684 \mathrm{x}$ $\log 10$ (height) - 78.387 [10]. This method for calculating body fat ratio is convenient, inexpensive and is very less time consuming.

With this background the aim of our study was to compare the results of the US Navy Seal formula and bioelectrical impedance methods to assess the body fat percentage in a group of medical students.

\section{Materials And Methods}

This was a cross-sectional study conducted on 85 medical students of Shifa College of Medicine in Islamabad, Pakistan, who volunteered for the study. All students gave verbal and written consent after being informed about the nature of study and measurements to be done. Students were asked to fast overnight before the day of body composition measurements and to empty bladders before 30 minutes of taking measurements. Moreover, students were also asked to refrain from strenuous physical activity one day prior to the experiment.

Digital scale and wall-mounted stadiometer were used to obtain the weight and height of each participant. Body composition measurements i.e., neck, waist and hip circumferences of all participants were recorded for the US Navy Seal formula. The data was collected by a trained operator using a measuring tape. The variables of age, gender, height, weight and hip, neck and waist circumferences were entered in the US Navy Seal Calculator to determine the percentage of body fat of each participant.

The participants were then asked to stand on the electrical impedance machine to determine the percentage of body fat of each participant. Leg-to leg bioelectrical impedance analysis (LBIA) of study participants was done by using a commercial glass diagnostic weighing machine (Beurer living glass diagnostic scale BG-42). Subjects were asked to stand vertically with bare feet on contact footpad electrodes of LBIA device. Body composition measurements such as lean mass and fat mass were recorded simultaneously by preprogrammed calculations automatically done by LBIA analyzer. All these measurements were taken using the instruments available in the college's Biochemistry lab. 


\section{Cureus}

The data obtained was analyzed on IBM's statistical package for the social sciences (SPSS) version 23 (IBM, Armonk, NY). Descriptive statistics were used to analyze and describe the data.

Frequencies and percentages were calculated for qualitative variables like gender whereas quantitative variables like age and body fat percentages were computed in mean and standard deviation (SD).

\section{Results}

Out of 85 study participants, there were 45 (53\%) male participants and 40 (47\%) female participants. The demographic data are displayed in Table 1.

\begin{tabular}{|c|c|c|}
\hline & Males & Females \\
\hline Age in years (mean $\pm S D)$ & $19.76 \pm 0.773$ & $19.47 \pm 0.960$ \\
\hline Height in cm (mean $\pm S D$ ) & $175.47 \pm 6.85$ & $160.05 \pm 5.90$ \\
\hline Weight in pounds (mean $\pm S D$ ) & $163.91 \pm 36.80$ & $132.69 \pm 36.70$ \\
\hline \multicolumn{3}{|l|}{ BMI, n (\%) } \\
\hline Underweight & $6(13)$ & $9(23)$ \\
\hline Normal & $24(53)$ & $14(35)$ \\
\hline Overweight & $8(18)$ & $12(30)$ \\
\hline Obese & $7(16)$ & $5(12)$ \\
\hline
\end{tabular}

\section{TABLE 1: Demographic data}

BMI: Body mass index; SD: Standard deviation

The male and female participants were divided into subgroups according to their BMI. The mean values of body fat percentage recorded by bioelectric impedance and calculated by the US Navy Seal formula were plotted on a bar graph for each subgroup in each gender. The results are in Figures $1-2$. 


\section{Cureus}

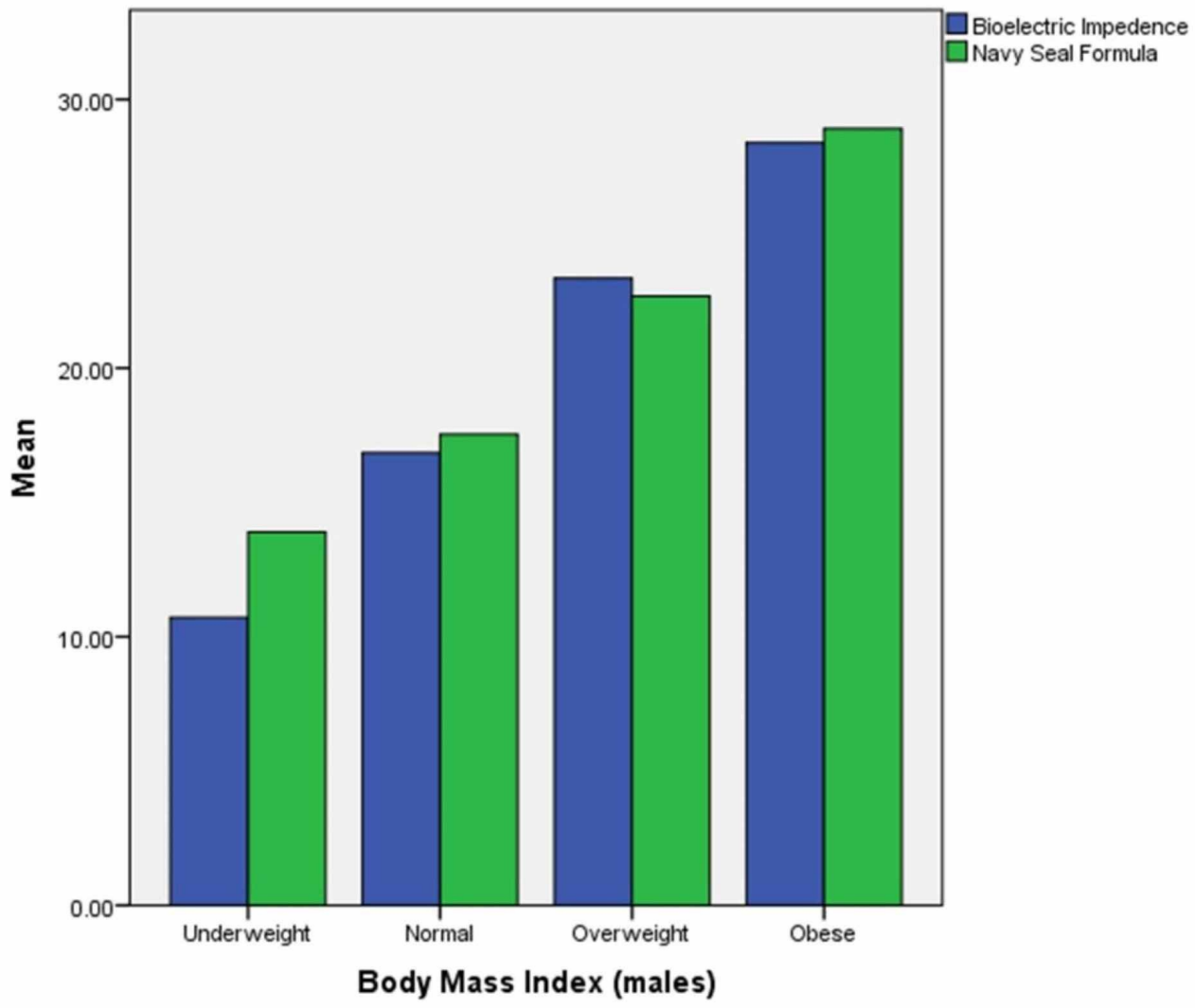

FIGURE 1: Body fat perccentage (males)

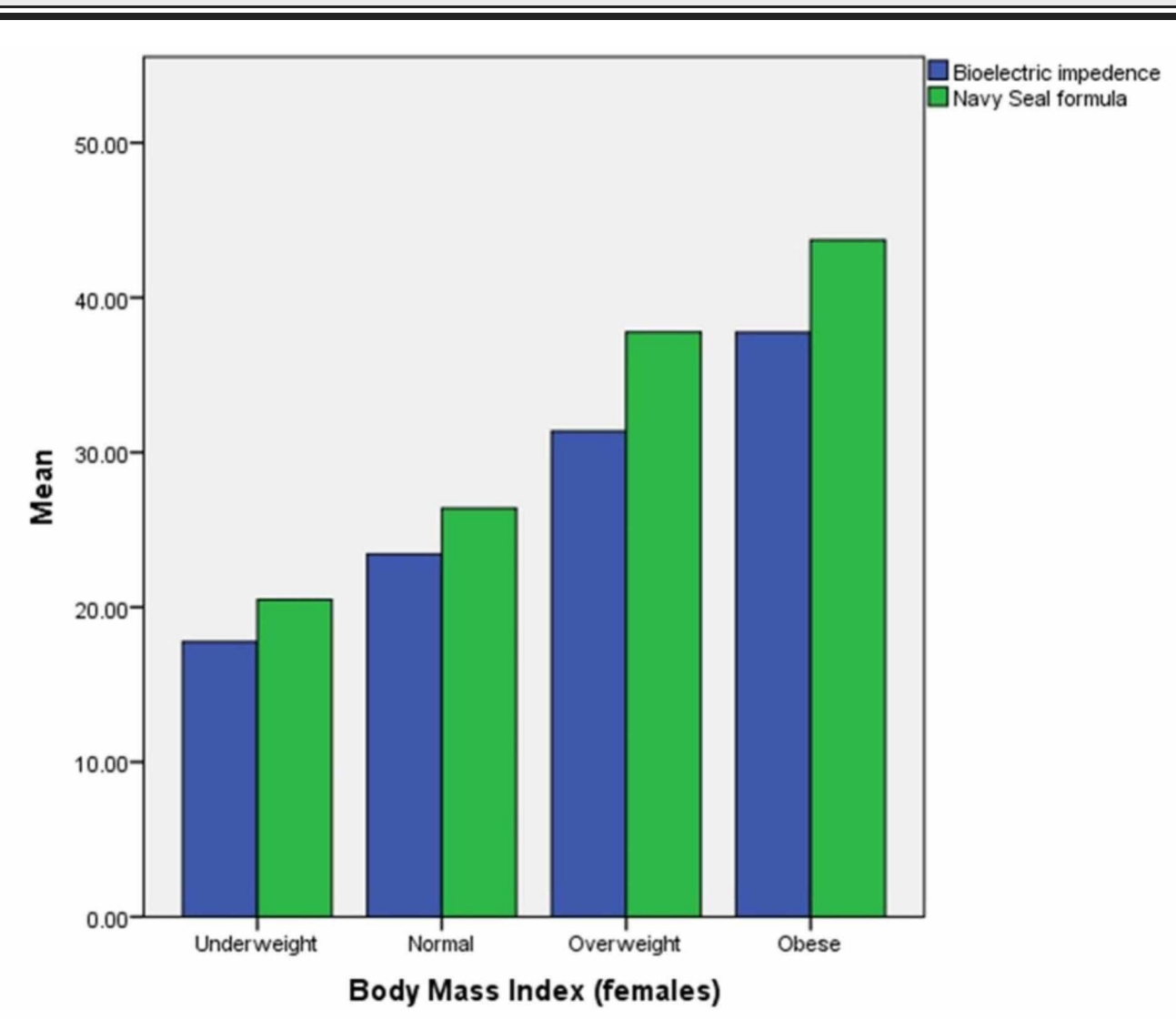

FIGURE 2: Body fat percentage (females) 


\section{Cureus}

The difference in mean body fat percentage was tested using chi-square test for each gender and each subsequent subgroup and method of recording. P value less than 0.05 was considered significant. In underweight males, the $\mathrm{p}$ value was 0.224 when mean body fat percentage was calculated by each method while in males with a normal BMI, the p value was 0.139 . In overweight males, the p value was 0.229 when mean body fat percentage was calculated by each method while in obese males, the $\mathrm{p}$ value was 0.227 .

In underweight females, the $\mathrm{p}$ value was 0.220 when mean body fat percentage was calculated by each method while in females with a normal BMI, the p value was 0.241 . In overweight females, the $\mathrm{p}$ value was 0.097 when mean body fat percentage was calculated by each method while in obese females, the $\mathrm{p}$ value was 0.213 .

The mean values of muscle mass in pounds recorded by bioelectric impedance and calculated by the US Navy Seal formula were plotted on a bar graph for each subgroup in each gender. The results are in Figures 3-4.

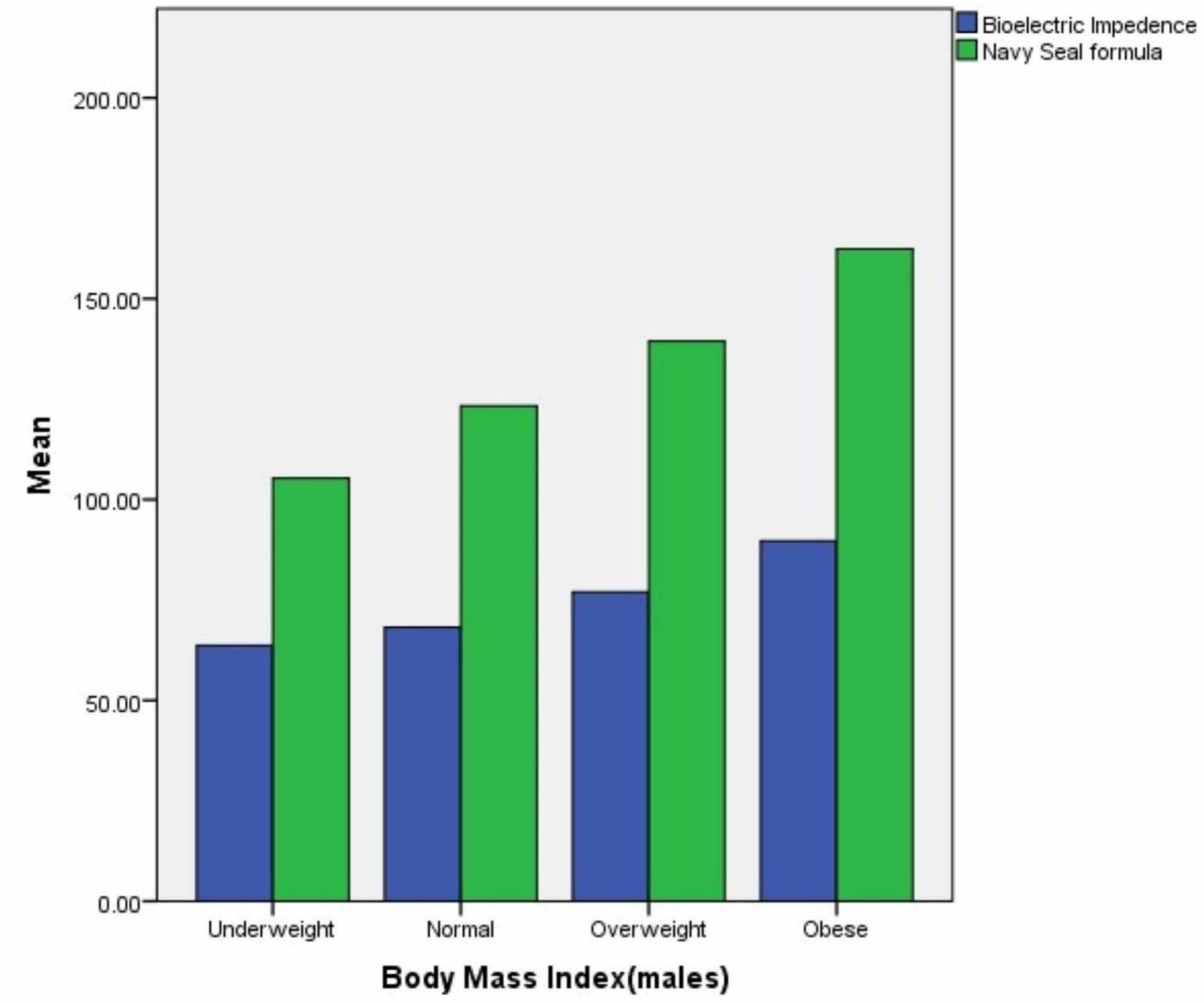

FIGURE 3: Muscle mass in pounds (males) 


\section{Cureus}

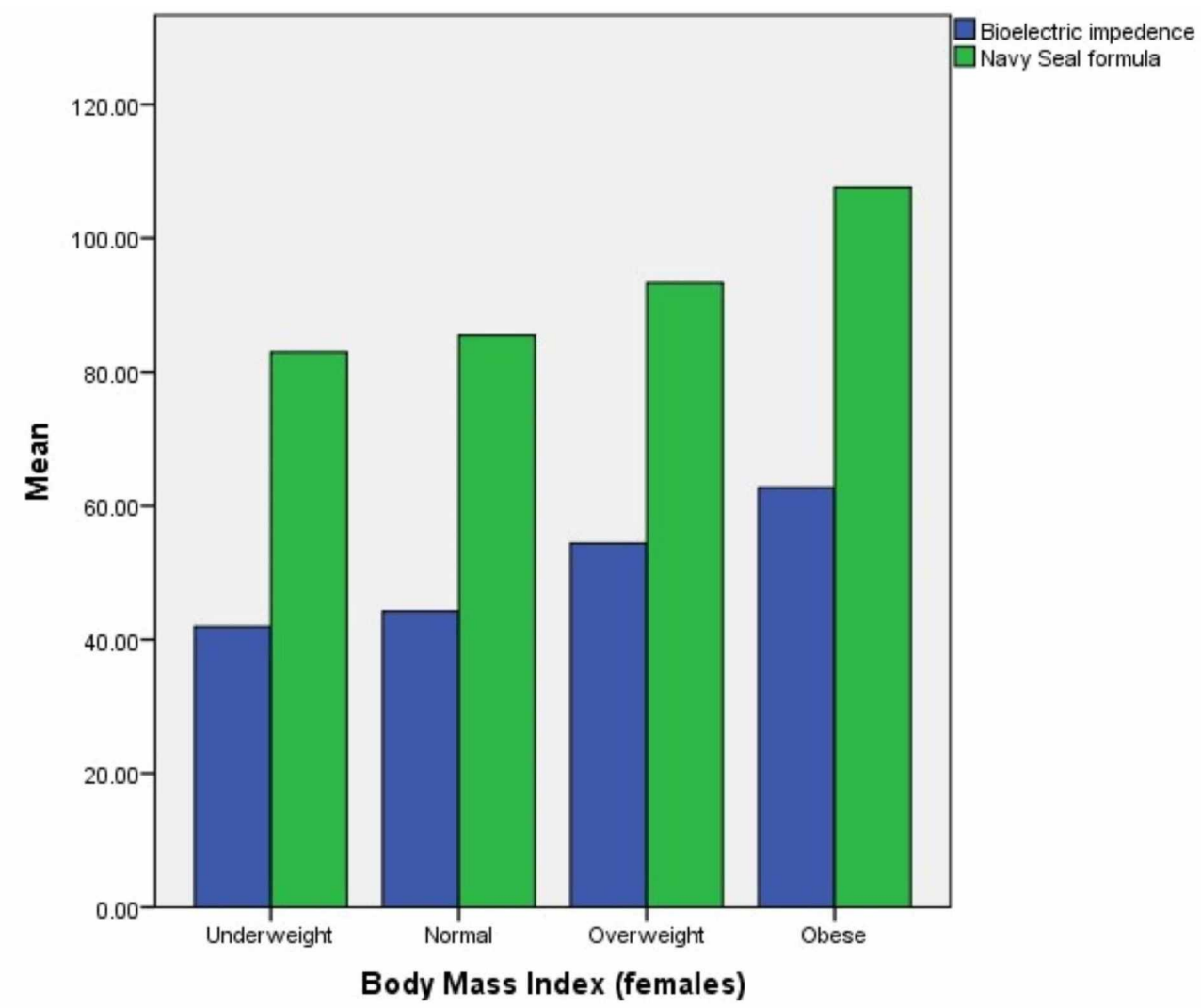

FIGURE 4: Muscle mass in pounds (females)

The difference in mean muscle mass in pounds was tested using t-test for each gender and each subsequent subgroup and method of recording. P value less than 0.05 was considered significant. In underweight males, the $\mathrm{p}$ value was 0.224 when mean value of muscle mass was calculated by each method while in males with a normal BMI, the $p$ value was 0.082 . In overweight males, the $p$ value was 0.229 when mean value of muscle mass was calculated by each method while in obese males, the $\mathrm{p}$ value was 0.227 .

In underweight females, the p value was 0.220 when mean value of muscle mass was calculated by each method while in females with a normal BMI, the p value was 0.253 . In overweight females, the $\mathrm{p}$ value was 0.083 when mean value of muscle mass was calculated by each method while in obese females, the $\mathrm{p}$ value was 0.213 .

\section{Discussion}

A very simple indicator of good health is BMI score and according to our results most of our study participants had normal BMI. Results of our study are in agreement with some other studies conducted in medical schools where the BMI of students was assessed [11]. Generally, medical students have a higher level of awareness about healthy diet and realize the importance of physical activities. As most of the undergraduate students are usually actively involved in sports in leisure time, therefore the majority of them usually have a normal BMI [12-13].

Considering the epidemic of obesity and associated co-morbidities worldwide, there is an increased need to monitor such changes in all age groups by inexpensive and reliable measurement tools [1415]. The Navy-seal formula and BIA are convenient, cost-effective and readily available methods which can be used as effective prevention and treatment strategies [16-17]. 
In our study, body fat ratios of males obtained by the BIA method compared to the ratios obtained by the Navy-seal method were statistically similar in every sub category of males according to the BMI; i.e. under weight, normal, weight, over weight and obese, respectively. The $\mathrm{p}$ value was considerably higher in the overweight and obese participant suggesting that the reliability of the two instruments also improves with the increase in BMI.

Similarly, body fat ratios of female participants obtained by using BIA were also statistically similar when compared to the ratios obtained by the Navy-seal method in every sub category of female participants according to the BMI categories. This shows that gender did not have any effect on the reliability of the two methods to measure body fat ratios.

The results of our study are not in agreement with the results of a study conducted on Japanese children which showed that low-body-mass females have high subcutaneous fat mass as compared to low body-mass males [18]. This can be partly because of the different metabolism and genetic body composition of Japanese people as opposed to Pakistani people.

However, in contrast to the male participants, the $\mathrm{p}$ values of the comparisons of the body fat ratios of the female participants revealed that the highest $\mathrm{p}$ values were obtained in the normal BMI category.

When we compared muscle mass of males in each BMI category, we observed that muscle mass ratio was similar in all BMI categories but the highest $\mathrm{p}$ values were obtained in overweight and obese participants. The results were in agreement with the body fat ratio results which had the highest reliability in overweight and obese participants. Similarly, although the muscle mass ratios obtained by both methods in females were statistically similar in all categories we had the highest $\mathrm{p}$ values in the underweight and normal weight participants.

Overall, we observed that the Navy-seal formula had slightly higher values for both muscle mass and body fat ratio in both genders and across all BMI categories in comparison to the BIA method, however, the differences were not statistically significant. To our knowledge, this comparison between results of the Navy-seal formula with BIA method to find out body composition has not been conducted before.

A limitation of using the bioelectric impedance device is that immediately after physical activity and intake of food and water, there might be a fluctuation in the results. In contrast, the results given for body composition given by the Navy-seal formula remain constant almost throughout the day and do not fluctuate with immediate physical activity and food and water intake [19]. The Navy-seal formula could be used at any time of the day whereas a major limitation of the BIA method is that users have to use at a specific time of a day.

\section{Conclusions}

According to results of this study, we conclude that the Navy seal formula and BIA are both quick, noninvasive and reliable instruments to measure body composition in adults and can be used as a screening tool for prevention and treatment of obesity at national level. Other measurement of body fat percentage by gold standard i.e., underwater weighing and DEXA could be difficult to perform on regular basis and costly. Moreover, the Navy-seal formula has the potential to be used as a screening tool whereas the BIA method can be used as a quick and easy method to gauge personal fitness goals.

\section{Additional Information \\ Disclosures}

Human subjects: Consent was obtained by all participants in this study. Institutional Review Board \& Ethics Committee, Shifa International Hospitals Ltd, Shifa Tameer-e-Millat University issued 
approval 903-178-2017. Dear Dr. Liaquat, We would like to inform that your study has been approved. The IRB/EC is in accordance with the ICH and GCP guidelines. Any changes in the protocol should be notified to the committee for prior approval. All the informed consents should be retained for reference (if applicable). A proper report should be submitted quarterly and final report after completion of the study to the IRB/ ethics committee. Sincerely, Dr. Ejaz Khan Chairman IRB and EC. Animal subjects: All authors have confirmed that this study did not involve animal subjects or tissue. Conflicts of interest: In compliance with the ICMJE uniform disclosure form, all authors declare the following: Payment/services info: All authors have declared that no financial support was received from any organization for the submitted work. Financial relationships: All authors have declared that they have no financial relationships at present or within the previous three years with any organizations that might have an interest in the submitted work. Other relationships: All authors have declared that there are no other relationships or activities that could appear to have influenced the submitted work.

\section{References}

1. Hruby A, Hu FB: The epidemiology of obesity: a big picture . Pharmacoeconomics. 2015, 33:673689. 10.1007/s40273-014-0243-X

2. Alberti KGMM, Eckel RH, Grundy SM, et al.: Harmonizing the metabolic syndrome: a joint interim statement of the International Diabetes Federation Task Force on Epidemiology and Prevention; National Heart, Lung, and Blood Institute; American Heart Association; World Heart Federation; International Atherosclerosis Society; and International Association for the Study of Obesity. Circulation. 2009, 120:1640-1645. 10.1161/CIRCULATIONAHA.109.192644

3. Olijhoek JK, Graaf YVD, Banga JD, Algra A, Rabelink TJ, Visseren FLJ: The metabolic syndrome is associated with advanced vascular damage in patients with coronary heart disease, stroke, peripheral arterial disease or abdominal aortic aneurysm. Eur Heart J. 2004, 25:342-348. 10.1016/j.ehj.2003.12.007

4. Wilson PWF, D’Agostino RB, Parise H, Sullivan L, Meigs JB: Metabolic syndrome as a precursor of cardiovascular disease and type 2 diabetes mellitus. Circulation. 2005, 112:3066-3072. 10.1161/CIRCULATIONAHA.105.539528

5. Grundy SM, Cleeman JI, Merz CNB, et al.: Implications of recent clinical trials for the National Cholesterol Education Program Adult Treatment Panel III guidelines. Circulation. 2004, 110:227239. 10.1161/01.CIR.0000133317.49796.0E

6. Katz EG, Stevens J, Truesdale KP, Cai J, Adair LS, North KE: Hip circumference and incident metabolic risk factors in Chinese men and women: the People's Republic of China study. Metab Syndr Relat Disord. 2011, 9:55-62. 10.1089/met.2010.0045

7. Tsimikas S, Willeit J, Knoflach M, et al.: Lipoprotein-associated phospholipase A2 activity, ferritin levels, metabolic syndrome, and 10-year cardiovascular and non-cardiovascular mortality: results from the Bruneck study. Eur Heart J. 2009, 30:107-115. 10.1093/eurheartj/ehn502

8. Kotler DP, Burastero S, Wang J, Pierson RN: Prediction of body cell mass, fat-free mass, and total body water with bioelectrical impedance analysis: effects of race, sex, and disease. Am J Clin Nutr. 1996, 64:489S-497S. 10.1093/ajcn/64.3.489S

9. Pietrobelli A, Heymsfield SB: Establishing body composition in obesity. J Endocrinol Invest. 2002, 25:884-892. 10.1007/BF03344052

10. Peterson DD: History of the U.S. Navy Body Composition program . Mil Med. 2015, 180:91-96. 10.7205/MILMED-D-14-00266

11. Alzayani S, Hamadeh RR: Body mass index and physical activity of medical students: a crosssectional study at the Arabian Gulf University. J App Life Sci Int. 2015, 3:1-6. Accessed: April 1, 2019:

http://www.journalrepository.org/media/journals/JALSI_40/2015/May/Alzayani312015JALSI17255.pd 10.9734/JALSI/2015/17255

12. Aziz J, Siddiqui NA, Siddiqui IA, Omair A: Relation of body mass index with lipid profile and blood pressure in young healthy students at Ziauddin Medical University. J Ayub Med Coll Abbottabad. 2003, 15:57-59.

13. Arsh A, Ali A, Ullah I, et al.: Body mass index in medical students and its association with gender and academic year. Pak J Physiol. 2017, 13:18-21.

14. Muralidhara DV, Pui C: An evaluation of overweight/obesity and body fat status in medical students. Integr Obesity Diabetes. 2015, 1:7-10. 10.15761/IOD.1000103

15. Hossain P, Kawar B, Nahas ME: Obesity and diabetes in the developing world--a growing 


\section{Cureus}

challenge. N Engl J Med. 2007, 356:213-215. 10.1056/NEJMp068177

16. Macias N, Alemán-Mateo H, Esparza-Romero J, Valencia ME: Body fat measurement by bioelectrical impedance and air displacement plethysmography: a cross-validation study to design bioelectrical impedance equations in Mexican adults. Nutr J. 2007, 15:6-18. 10.1186/1475-2891-618

17. Wang L, S Hui SS, Wong SH: Validity of bioelectrical impedance measurement in predicting fatfree mass of Chinese children and adolescents. Med Sci Monit. 2014, 20:2298-2310. 10.12659/MSM.890696

18. Komiya S, Eto C, Otoki K, Teramoto K, Shimizu F, Shimamoto H: Gender differences in body fat of low- and high-body-mass children: relationship with body mass index. Eur J Appl Physiol. 2000, 82:16-23. 10.1007/s004210050646

19. Androutsos O, Gerasimidis K, Karanikolou A, Reilly JJ, Edwards CA: Impact of eating and drinking on body composition measurements by bioelectrical impedance. J Hum Nutr Diet. 2015, 28:165171. Accessed: May 8, 2019: https://onlinelibrary.wiley.com/doi/abs/10.1111/jhn.12259. 10.1111/jhn.12259 